\title{
Two Oudemansiella from a forest fragment in Southwestern Amazonia
}

\author{
Wartchow $\mathrm{F}^{1}$,Teixeira-Silva $\mathrm{M}^{2}$, Ribeiro $\mathrm{MJ}^{3}$ and Ribeiro $\mathrm{SAL}^{3}$ \\ ${ }^{1}$ Universidade Federal da Paraíba, Departamento de Departamento de Sistemática e Ecologia, CEP: 58051-970, João \\ Pessoa, PB, Brazil. \\ ${ }^{2}$ Universidade Federal do Paraná, Programa de Pós-graduação em Botânica, 19031, CEP 81531-980, Curitiba, \\ Paraná, Brazil. \\ ${ }^{3}$ Universidade Federal do Acre, Departamento de Biologia, Campus Universitário, Distrito Industrial, CEP: 69915 - \\ 900, Rio Branco, AC, Brazil.
}

Wartchow F, Teixeira-Silva M, Ribeiro MJ, Ribeiro SAL 2014 - Two Oudemansiella from a forest fragment in Southwestern Amazonia. Mycosphere 5(1), 172-178, Doi 10.5943/mycosphere/5/1/8

\begin{abstract}
Oudemansiella macracantha and O. steffenii are reported for the first time from the State of Acre, North Brazil. We also discuss the importance of the slenderness of basidiomes and characteristics of the basidiospores for species segregation. Descriptions, discussions and drawings are also provided here.
\end{abstract}

Key words - Agaricales - Agaricomycetes - Neotropic - Phylaracriaceae - taxonomy

\section{Introduction}

Systematic of xerulloid/oudemansielloid taxa were recently drastically changed, with eight genera erected: Dactylosporina (Clémençon) Dörfelt, Hymeniopellis R.H. Petersen, Mucidula Pat., Oudemansiella Speg., Paraxerula R.H. Petersen, Ponticulomyces R.H. Petersen, Protoxerula R.H. Petersen and Xerula Maire (Petersen \& Hughes 2010). However, other authors as such Wang et al. (2008) and Yang et al. (2009) considered only three genera: Xerula s.str., Oudemansiella (comprising Dactylosporina, Hymeniopellis, Mucidula, Oudemansiella s.str., Ponticulomyces and Protoxerula) and an unnamed clade including Xerula americana Dörfelt [= Paraxerula americana (Dörfelt) R.H Petersen]. The main point argued by Petersen \& Hughes (2010) against the position of the Chinese authors was the lack of phylogenetic results in their works, which are only cited, not shown in their articles. Recently phylogenetic analysis by the first author (F. Wartchow \& G.A. Silva unpub. data) corroborate with Yang et al. (2009) generic concept. So, here we prefer to use the generic concept by Yang et al. (2009), as previously adopted by Wartchow et al. (2010) for the echinulate spored taxa of Oudemansiella.

In Brazil Oudemansiella is frequently reported in several states. Since studies by Singer (1945 as O. echinospora Singer, 1953) O. steffenii (Rick) Singer was reported, and being considered as the most widely distributed taxon. Oudemansiella cubensis (Berk. \& M.A. Curtis) R.H. Petersen [as O. canarii (Jungh.) Höhn.], O. radicata s. l., O. subnigra and O. macracantha were also reported from this country (Singer 1964, 1989, Putzke \& Pereira 1988, Capelari \& Gugliotta 2005, Wartchow et al. 2010, Petersen \& Hughes 2010). Recent citation of these taxa was given by Wartchow et al. (2010), who also discussed the differences in species concept between 
Oudemansiella steffenii and O. macracantha Singer and concluded that features of the basidiospores and the basidioma are important for segregate both species.

Studies on agarics in the State of Acre, North Brazil, are very fragmented. Some of the few records are reported by Bononi (1992), with Lepiota citrinella Speg, Filoboletus gracilis (Klotzch ex Berk.) Singer, and unidentified members of Agaricus L. : Fr., Marasmius Fr., Mycena and Pleurotus Fr. The genus Oudemansiella Speg. is infrequently reported from Brazilian Amazon. Singer (1989) described O. subnigra Singer from the State of Amazonas, later considered a probably synonym of Xerula setulosa (Murrill) R.H. Petersen by Petersen \& Hughes (2010); Souza \& Aguiar (2004) and Wartchow et al. (2010) reported O. steffenii (Rick) Singer from the States of Amazonas and Rondônia, respectively.

Here we report two taxa of Oudemansiella with echinulate basidiospores for the first time from the State of Acre, Southwestern Amazonia.

\section{Materials \& Methods}

The specimens were collected at 'Reserva Experimental Catuaba' $\left(10^{\circ} 04^{\prime} \mathrm{S}\right.$ and $\left.67^{\circ} 37^{\prime} \mathrm{W}\right)$, with an area about 2111 ha. Its vegetation is constituted mainly of 'terra firme' rain forest, but also including open areas with bamboo, secondary forests, and pastures (see summary in Souza et al. 2008)

Microscopic observations were made from material mounted in $3 \% \mathrm{KOH}$ and Congo Red solutions. Presentation of basidiospore data follows the methodology proposed by Tulloss et al. (1992), but slightly modified by Wartchow (2012) and Wartchow et al. (2012). Twenty five basidiospores were measured for statistics. Abbreviations include $\mathbf{L}(\mathbf{W})=$ basidiospore length (width) average, $\mathrm{Q}=$ the length : width ratio range as determined from all measured basidiospores, and $\mathbf{Q m}=$ the $\mathbf{Q}$ value averaged from all basidiospores measured. Herbarium codes follow Thiers (2014).

\section{Taxonomy}

Oudemansiella macracantha Singer, Sydowia 15: 59. 1962 ('1961').

Figs. $1-2,4-8$

Basidiome very tall and slender, solitary. Pileus about $12 \mathrm{~mm}$ in diam., plane, brown, surface radially slightly rugulose; margin smooth; context very thin, fleshy. Lamellae adnexed, dirty white, very narrow, distant; edge smooth, grayish; lamellulae very common, truncate. Stipe up to $95 \times 2 \mathrm{~mm}$, concolorous to pileus (but white when fresh, according to field notes); at base apparently slightly inflated, not truly bulbous; pseudorrhiza detached from the basidiome in the moment of collection; context very thin, apparently solid.

Basidiospores (9.3-) 12-15.3 (-16.6) × (8.6-) 10.6-14.6 $\mu \mathrm{m}$ (excluded spines), $\mathbf{L}=13.4$ $\mu \mathrm{m}, \mathbf{W}=12.5 \mu \mathrm{m}, \mathrm{Q}=1.00-1.14(-1.32), \mathbf{Q m}=1.07$, inamyloid, colorless, globose to subglobose only occasionally ellipsoid (only once observed), moderately thick walled, strongly spinose with about 23 spines 2.5-5.3 (-6.5) $\mu \mathrm{m}$ long, subacute to subobtuse, very occasionally with acute tips, with guttulate contents; hilar appendix broadly obtuse. Basidia 46-55 × 16-20 $\mu \mathrm{m}$, clavate, mostly 4-sterigmata to $9 \times 4.5 \mu \mathrm{m}$ (width measured at base), clamped. Pleurocystidia not abundant, 40-73 $\times 20-33 \mu \mathrm{m}$, fusoid-lageniform frequently broadly mucronate at apex or sometimes also truly capitulate; frequently colorless mostly thin-walled or occasionally thickening to $1 \mu \mathrm{m}$; sometimes extracellular refringent fine incrustation at apex. Cheilocystidia not seen. Lamella trama regular with filamentous hyphae frequently septate, $4-10 \mu \mathrm{m}$, colorless, thin walled, occasionally clamped. Pileipellis hymeniform, composed by rounded, or nearly so, pedicelate pileocystidia with rounded apex or elongate clavate to $40-56 \times 14.5-22 \mu \mathrm{m}$ (measured at apex), pedicel to $20 \mu \mathrm{m}$ long, with brownish or pale diffuse to sometimes condensed pigment, thin-walled or about $1 \mu \mathrm{m}$ thick, frequently clamped at base. Stipe context with filamentous hyphae frequently septate, 4-10 (-21) $\mu \mathrm{m}$ wide, longitudinally orientated, occasionally clamped. Stipitipellis at midstipe arising from the pellis, solitary or in small tuffs of three or four cystidia, ranging to $40-192 \times 13-20 \mu \mathrm{m}$, pale 


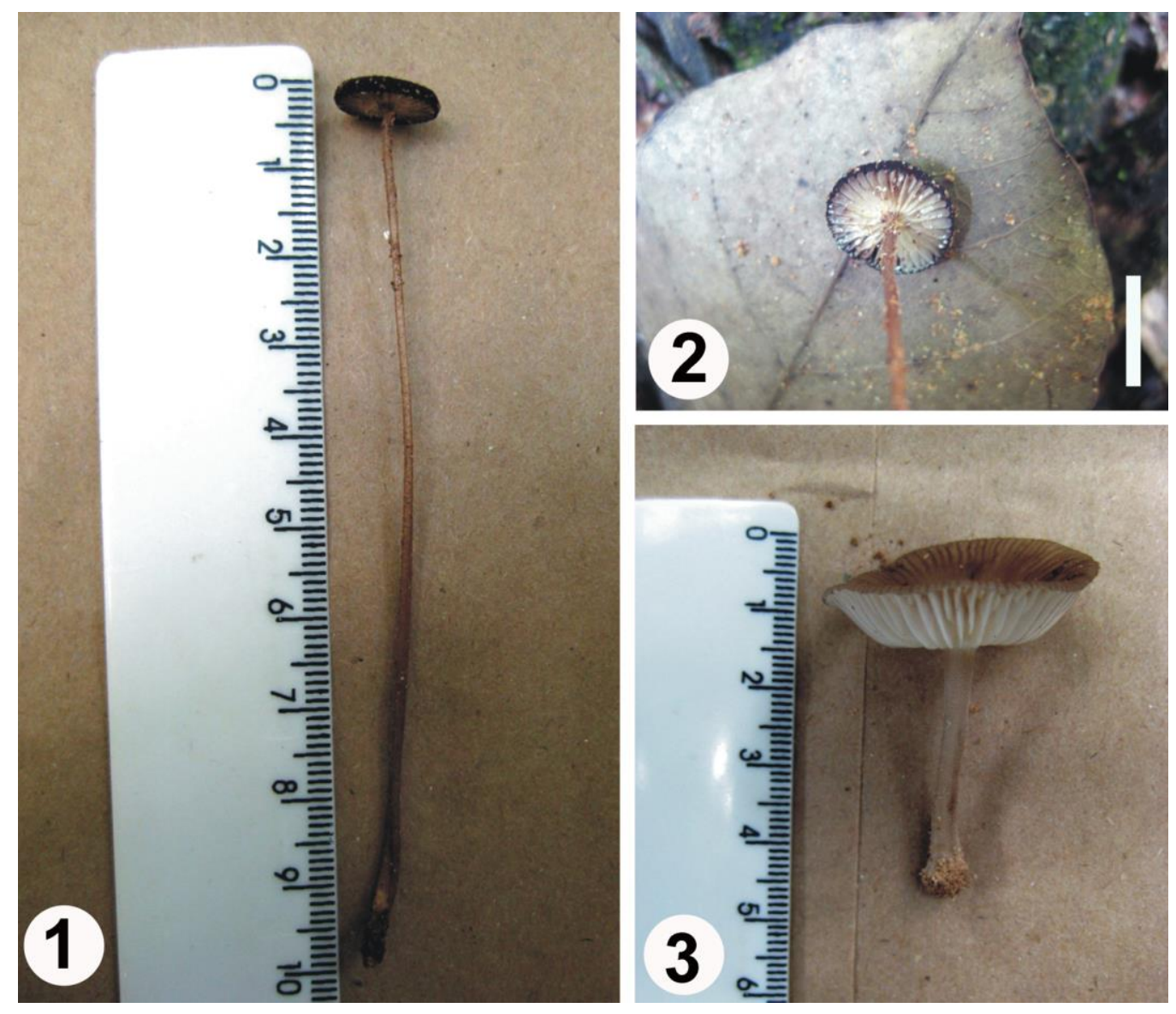

Figs 1-3 - O. macracantha and $O$. steffenii. 1, basidiome of $O$. macracantha (UFACPZ 18617). 2 , Detail of the lamellae and top of stipe of $O$. macracantha (UFACPZ 18617). 3, basidiome of $O$. steffenii (UFACPZ 18637). - Bar $=10 \mathrm{~mm}$. Photo by M.A. Teixeira.

colored to also frequently condensed brownish pigmented thin-walled or thickening to $1 \mu \mathrm{m}$, cylindrical and the shortest ones fusoid-lageniform, common; at apex also present and similar in size and shape.

Distribution - see remarks.

Material examined - Brazil, Acre, Senador Guiomard, Reserva Experimental Catuaba, solitary on soil (attached to buried rotting wood?) in fragmented Amazon forest, 20 March 2010, M.A. Teixeira, I.O. Cruz \& T. Farias s.n. (UFACPZ 18617).

\section{Discussion}

When Singer (1962) protologued O. macracantha, he only used the length of spines for differentiate this taxon from O. stefenii. Later, Singer (1964) also included the number of spines (about 23 in this taxon) and slenderness of stipe as important for species concept. However, recent studies by Petersen \& Hughes (2010) did not agree with the use of basidiospore' spines features for species segregation, but they concur that size and slenderness of the basidiome are useful for it (the pileus diameter of $O$. macracantha is distinctly smaller than $O$. steffenii). They also mentioned two other characters for species segregation that in our opinion are much tenuous as showed below:

- the lamellae color: they considered $O$. macracantha as having white lamellae in comparison to cream in $O$. steffenii, but in our collections we noted that it is cream or dirty-white;

- the marginate lamella edge: Petersen \& Hughes (2010) clearly reported that in $O$. macracantha, it is dark brown colored, differently what occurs in O. steffenii, that is not marginate. However, recent collection of O. steffenii described by Wartchow et al. (2010) brownish tints at edge was reported. 
Regarding these points, the lamellae features (viz., color and edge) are not consistent for species segregation.

Referring microscopic features of the basidiospores, Petersen (2008) and Petersen \& Hughes (2010) reported that numbers of spines of $O$. macracantha are more numerous than $O$. steffenii. Singer $(1964: 155,158)$, on the other hand, clearly referred in the descriptions of both taxa that in $O$. steffeni the number of spines range 38-42 while $O$. macracantha only about 23 . The comparison was made after analysis of material from Argentina and Mexico, not from the type or any material collected in the type region (Bolivian Amazon). In addition, the basidiospores pictured by Petersen (2008) have spines not or only slightly larger than to scale bar of $2 \mu \mathrm{m}$ showed in the pictures, and much numerous in comparison to our material and the type analyzed by Wartchow et al. (2010).

In our opinion, the wide distribution of $O$. macracantha reported by Petersen \& Hughes (2010), from Argentina, Bolivia, Brazil (in the State of Paraná), Colombia, Mexico, Panama and Venezuela needs to be revised for the following reasons: (1) the drawings (Petersen \& Hughes 2010: 72) are based exclusively on materials collected in Bolivia (including the type and other recent material), and noting about the other materials; (2) the description is apparently also based on Bolivian materials, reporting the number of spines by basidiospores the same to Singer (1964), Wartchow et al. (2010) and the material presented here.

In early article, Petersen (2008) apparently reported Mexican and Argentinean materials of 'Xerula macracantha' possessing much more spines than Petersen \& Hughes (2010), about 40 according to our count in Petersen (2008 figs. 93-96). The Brazilian Amazon collection of $O$. macracantha agrees in all aspects to one described by Singer (1964) and later Wartchow et al. (2010), and the drawings of Bolivian material in the type studies by Petersen \& Hugher (2010). So, we reinforce the original concept by Singer $(1962,1964)$ that number and length of spines of that taxon is very important character for species confirmation, in addition to the much more slender and elongated stipe. Even so, the distribution might be restricted from the 'Departamentos' of Beni and Pando, Bolivia and the State of Acre, Brazil.

Other point that is needed to discuss here is the question of the typification of $O$. macracantha. Petersen \& Hughes (2010) and Wartchow et al. (2010) published their typification almost simultaneously, in October 2010. Both had convinced explanation to do it: the first work proposed a neotypification while the second a lectotypification. In the case of the type designation of $O$. macracantha, it can have an ambiguous interpretation: Petersen \& Hughes (2010) considered that remaining material cannot be considered as a paratype and made the neotypify; Wartchow et al. (2010), on the other hand, based in the Art. 9.12 of the International Code of Nomenclature for algae, fungi, and plants (McNeill et al. 2012), argued that Singer's material, due collected prior of protologue in 1956, can be treated as part of the uncited original material of the species and consequently lectotypified it. Even so, both typifications are correctly interpreted.

Oudemansiella stefenii (Rick) Singer, Lilloa 26: 66. 1953.

Fig 3.

Material examined - Brazil, Acre, Senador Guiomard, Reserva Experimental Catuaba, solitary on soil (attached to buried rotting wood?) in fragmented Amazon forest, 2008, M.A. Teixeira \& I.O. Cruz s.n. (UFACPZ 18637).

Extralimited material examined - Brazil, Pernambuco, Recife, Mata de Dois Irmãos, solitary on soil (attached to buried rotting wood?) in fragmented Amazon forest, 03 July 2003, F. Wartchow 10/2006 (URM 80090).

Notes - This material agrees in all aspects with the descriptions by Singer (1964), Pegler \& Young (1986), Corner (1994), Capelari \& Gugliotta (2005), Petersen and Hughes (2010) and Wartchow et al. (2010). Here we can provide an update on the species distribution in Brazil: Rio Grande do Sul (Singer 1945, 1953, 1964, Putzke \& Pereira 1988, Wartchow et al. 2010), Rio de Janeiro (Corner 1994), São Paulo (Capelari \& Gugliotta 2005), Pernambuco (Singer 1964, Wartchow et al. 2010), Amazonas (Souza \& Aguiar 2004), Rondônia (Wartchow et al. 2010) and now for the first time from Acre. 


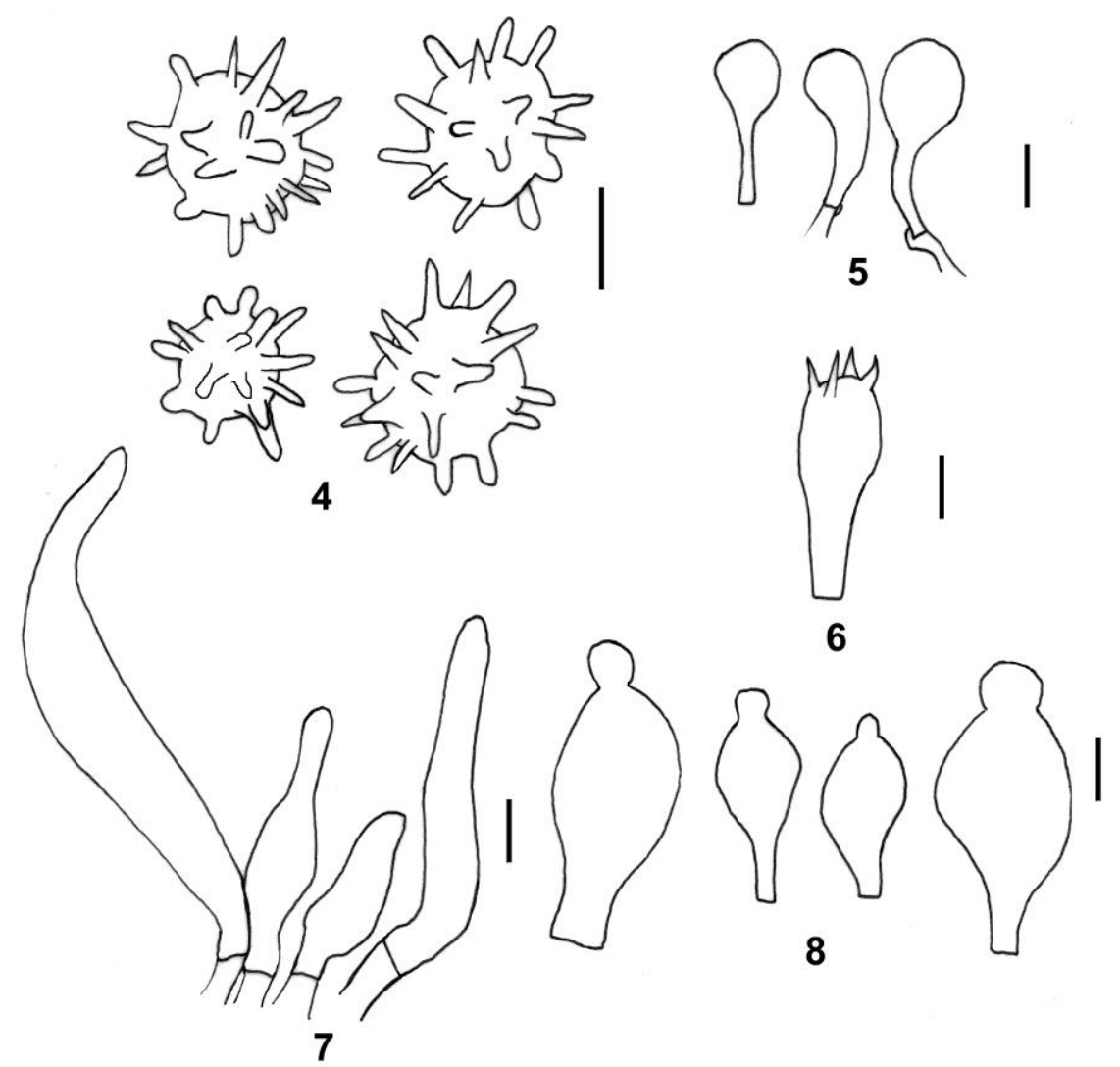

Figs 4-8 - O. macracantha (UFACPZ 18617). 4, Basidiospores. 5, Pileocystidia. 6, Basidium. 7, Caulocystidia. 8 Pleurocystidia. - Bars $=10 \mu \mathrm{m}$.

\section{Discussion about basidiome slenderness for segregate $O$. macracantha and $O$. steffenii}

The slenderness of the basidiome of the two taxa cited here is widely accepted for species segregation (Singer 1964, Petersen and Hughes 2010, Wartchow et al. 2010). Heinemann (1983 86) developed a biometric formula for measure the index of gracility (IG) for the genus Micropsalliota Höhn., which he considered very important for separate it in several supraspecific unnamed groups. Here we reproduce it for subsequent discussion:

$$
\mathrm{IG}=\mathrm{St}^{2} \cdot(\mathrm{D} \cdot \mathrm{d})^{-1} \text {, where: }
$$

$\mathrm{IG}=$ index of gracility

$\mathrm{St}=$ stipe length

$\mathrm{D}=$ diameter of pileus

$\mathrm{d}=$ diameter of stipe

One example of slender basidiome for $O$. steffenii is the material URM 8009, with pileus 40 $\mathrm{mm}$ in diam. and stipe $130 \times 3 \mathrm{~mm}$ long. It can be compared with our material of $O$. macracantha that has somewhat shorter stipe in comparison to Singer (1964) description (95 mm against 122 $\mathrm{mm}$ long). Anyway, the IG of $O$. macracantha (IG>350) is much higher than the more slender collection of $O$. steffenii (URM 80090), that has IG $=140$.

The use of basidiome slenderness and the number of spines per basidiospore can be summarized in the key for differentiation of both taxa:

1a. IG maximum range to 140 ; basidiospores with $>30$ spines and rarely longer than $3.5 \mu \mathrm{m}$ long. O. steffenii 1b. IG up to 350; basidiospores with about 20-23 spines that range 3-5.5 $\mu \mathrm{m}$ long. O. macracantha 


\section{Acknowledgements}

We wish thank Dr. Clark L. Ovrebo for pre-submission review of the manuscript. Irailse O. Cruz and Thays Farias are kindly acknowledged by help in collections of materials examined here, and Dr. Maria Regina Barbosa and Taxon laboratory for the use of study and facilities.

\section{References}

Bononi VLR. 1992 - Fungos macroscópicos de Rio Branco, Acre, Brasil. Hoehnea 19, 31-37.

Capelari M, Gugliotta AM. 2005 - Dactylosporina e Oudemansiella (Tricholomataceae, Oudemansielinae) do Parque Estadual das Fontes do Ipiranga (PEFI), São Paulo, SP. Hoehnea 32, 381-387.

Corner EJH. 1994 - On the agaric genera Hoehembuehelia and Oudemansiella Part II: Oudemansiella Speg. Gardner Bulletin of Singapore 46, 49-75.

Heinemann P. 1983 - Clé de determination de Micropsalliota (Agaricaceae) et description de deux speces nouvelles. Bulletin du Jardin Botanique National de Belgique 53, 85-95.

McNeill J, Barrie FR, Buck WR, Demoulin V, Greuter W, Hawksworth DL, Herendeen PS, Knapp S, Marhold K, Prado J, Prud'Homme van Reine WF, Smith GF, Wieresma JH, Turland NJ, (Eds.). 2012. International Code of Nomenclature for algae, fungi, and plants. Regnum Vegetabile 154. Koeltz Scientific Books, Koegnistein (http://www.iapttaxon.org/nomen/main.php). Accessed 31 August 2013.

Pegler DN, Young TWK. 1986 - Classification of Oudemansiella (Basidiomycota: Tricholomataceae), with special reference to spore structure. Transactions of the British Mycological Society 87, 583-602.

Petersen RH. 2008 - Scanning electron microscope images of basidiospores of Xerula (Physalacriaceae, Agaricales). Mycoscience 49, 19-34.

Petersen RH, Hughes KH. 2010 - The Xerula/Oudemansiella complex (Agaricales). Beihefte zur Nova Hedwidia 137, 1-625.

Putzke J, Pereira AB. 1988 - O gênero Oudemansiella Speg. no Rio Grande do Sul, Brasil. Cadernos de Pesquisa Série Botânica 1, 47-69.

Singer R. 1945 - New and interesting species of Basidiomycetes. Mycologia 37, 425-439.

Singer R. 1953 - Type studies on Basidiomycetes. VI. Lilloa 26, 57-159.

Singer R. 1962 ('1961') - Diagnosis fungorum novorum agaricalium. II. Sydowia, 15, 45-83.

Singer R. 1964 - Oudemansiellinae, Macrocystidiinae, Pseudohiatulinae in South America. Monographs of South American Basidiomycetes especially those of the east slope of the Andes and Brazil. VIII. Darwiniana 13, 145-190.

Singer R. 1989 - New taxa and new combinations of Agaricales (Diagnoses Novorum Agaricalium IV). Fieldiana Botany 21, 1-133.

Souza HQ, Aguiar IJA. 2004 - Diversidade de Agaricales (Basidiomycota) na reserva biológica Walter Egler, Amazonas, Brasil. Acta Amazonica 34, 43-51.

Souza VM, Souza MB, Morato EF. 2008 - Efeitos da sucessão florestal sobre a anurofauna (Anphibia: Anura) da Reserva Catuaba e seu entorno, Acre, Amazônia sul-ocidental. Revista Brasilera de Zoologia 25, 49-51.

Thiers B 2014 [continuously updated] - Index Herbariorum: A global directory of public herbaria and associated staff. New York Botanical Garden's Virtual Herbarium. (http://sweetgum.nybg.org/ih/). Accessed 30 January 2014.

Tulloss RE, Ovrebo CL, Halling RE. 1992 - Studies on Amanita (Amanitaceae) from Andean Colombia. Memoirs of the New York Botanical Gardner 66, 1-46.

Wang L, Yang Z-L, Zhang L-F, Mueller G.M. 2008 - Synopsis and systematic reconsideration of Xerula s. str. Acta Botanica Yunnanica 30, 631-644.

Wartchow F. 2012 - Clavulina incrustata, a new species from Pernambuco, Brazil. Cryptogamie, Mycologie 33, 105-113. 
Wartchow F, Pereira J, Drechsler-Santos ER, Gomes-Silva AC, Tiago PV, Putzke J, Cavalcanti MAQ. 2010 - Two Oudemansiella species with echinulate basidiospores from South America with O. macracantha lectotypified. Mycotaxon 113, 119-127.

Wartchow F, Buyck B, Maia LC. 2012 - Cantharellus aurantioconspicuus (Cantharellales), a new species from Pernambuco, Brazil. Nova Hedwigia 94, 129-137.

Yang Z-L, Zhang L-F, Mueller GM, Kost G.W, Rexer K-H. 2009 - A new systematic arrangement of the genus Oudemansiella s. str. (Physalacriaceae, Agaricales). Mycosystema 28, 1-13. 